\title{
Numerical Study of the Flow in Rotor-Stator of Francis Turbine
}

\author{
Ezz Eldin Mohamed Hefny \\ Hydro Power Genration Company \\ High-Dam Power Station \\ Aswan, Egypt \\ zizohefny1@gmail.com \\ Waleed Ahmed Abdelfadeel \\ Mech. Power Engineering Dept. \\ Faculty of Energy Engineering \\ Aswan University - Aswan, Egypt \\ wfadeel@yahoo.com
}

\author{
Tarek Mekhail \\ Mech. Power Engineering Dept. \\ Faculty of Energy Engineering \\ Aswan University - Aswan, Egypt \\ tmalak@aswu.edu.eg \\ Ibrahim Kamal Mohamed \\ Faculty of Engineering at Rabigh \\ King Abdulaziz University, KSA \\ Mech. Power Engineering Dept \\ Faculty of Energy Engineering \\ Aswan University - Aswan, Egypt \\ mohamed7up2000@yahoo.com
}

\begin{abstract}
This study focuses on the aspects of rotor-stator interaction in a realistic prototype Francis turbine for two main load settings. The study used a state-of-the-art computational fluid dynamics technique to simulate the flow in the whole turbine. The method used in this study is based on solving the Reynolds-averaged Navier-Stokes equations with the turbulence model $k-\varepsilon$. The flow parameters such as velocity and pressure are analyzed to show the main flow characteristics within the turbine components. Pressure signals at some points within the turbine are analyzed to find out the primary and the secondary frequencies of the pressure signal. Comparing the measurement of the pressure with the simulations revealed that the computational solution is in good comparison with the measurement. Fast Fourier transform algorithm is applied to the pressure signals sampled from some points in the turbine in order to find out the inherent frequencies. These pressure frequencies are important to find the resonance possibilities. The study gave two important deliverables for the operation and design of this specific Francis turbine. The first one is the actual geometry of the turbine and the second one is the database of the computational solution. These two deliverables can be used for future research and analysis of the Francis turbine.
\end{abstract}

Keywords- Francis turbine; rotot-statot interaction; CFD; turbulent flow

\section{INTRODUCTION}

Francis turbine is one of the hydraulic turbines (such as Pelton and Kaplan) which is considered as the heart of any hydropower plant responsible for the plant overall efficiency [1]. Generally, it converts the hydraulic energy available from flowing water into mechanical energy at in a form of rotating shaft. Francis turbine is distinguished from the impulse turbine, where the total head of the incoming fluid is converted into an equivalent velocity head at the exit of the supply nozzle. Francis turbine is a reaction turbine, where the rotation of runner or rotor is mainly due to the impulse action as well as the change in pressure over the runner blades.

One of the most important factors in the design and operation of Francis turbine is the so called Rotor-Stator Interaction (RSI). In a Francis turbine, RSI is actually a direct result of the flow passing through the Francis turbine components, i.e., cascade of stay vanes, guide vanes, and runner blades [2]. Although the runner is mainly rotating at a constant angular speed, to match the generated electric frequency during steady state condition, an unsteady exchange of momentum takes place between the guide vane trailing edge and leading edge of the runner blade[3]. This complex interaction between the runner blades and guide vanes leads to a propagated sound wave in all direction of the turbine [5]. The term RSI is used in the turbomachinery community to refer to this complex interaction between the runner blades and guide vanes. Figure 1 shows the complex interaction and exchange of momentum between guide vanes and runner blades.

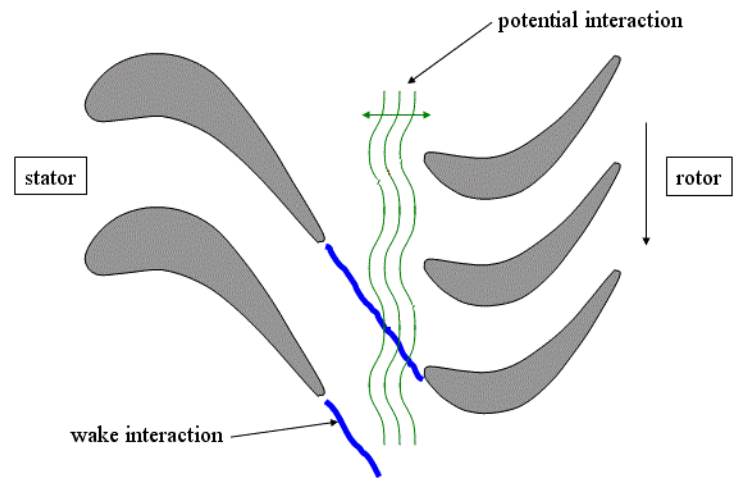

Fig. 1. Rotor-stator interactions

The RSI arising from the unequally distributed flow of guide vanes and runner blades eventually produces pressure fluctuations in turbine with different frequency in both the stationary and rotating domain (diametrical pressure mode). This occasionally causes hydromechanics resonance between the rotating diametrical pressure mode and the impeller and head cover structure and this in turn induces strong vibrations and noise [3]. Such complications affects the whole system and may cause failure and fatigue for the turbine components [6].

The RSI frequency depends mainly on the number of guide vanes $\left(Z_{g v}\right)$, the number of runner blades $\left(Z_{b}\right)$, and the angular speed of the runner $(n)$ [7]. It can be formulated using (1) the frequency in the stationary domain (blade passing frequency) and using (2). 


$$
\begin{gathered}
f_{R S I, s t}=\frac{n Z_{b}}{60} \\
f_{R S I, r o t}=\frac{n z_{g v}}{60}
\end{gathered}
$$

The main aim of this study is to investigate the rotor-stator interaction in a full scale Francis turbine under different operating conditions over a particular power generation range. The real measurements of the power plant are utilized to set the required boundary conditions of the model used here. The actual geometrical dimensions will be used to form the model. Since it is almost impossible to do such a study on the physical turbine, a numerical model using the so called CFD technique will be used to calculate the flow inside the Francis turbine with all its parameters.

\section{MethodOLOGY}

\section{A. CFD model}

The CFD model Fluent (ANSYS® Academic Research Mechanical, Release 16.1) is adopted for this study.

\section{B. Geometry Modelling}

The geometry consists of a stator (two rows of blade stay vanes, 12 , and moving blades, 24 , which determine the wicket gate opening used to identify the part load and the full load condition), a runner (13 blades), and a draft tube. The software SOILDWORKS is used to generate the full 3D model for the whole model, as shown in Fig. 2. The flow enters to the domain through the stator periphery filling the space between the guides vans towards the rotor center then exits the draft tube. Finally, to check that the model is set correctly, errors such as duplicate lines, isolated lines, surface holes, reliefs, etc. is checked using the Check Geometry tool provided in SOLIDWORKS.

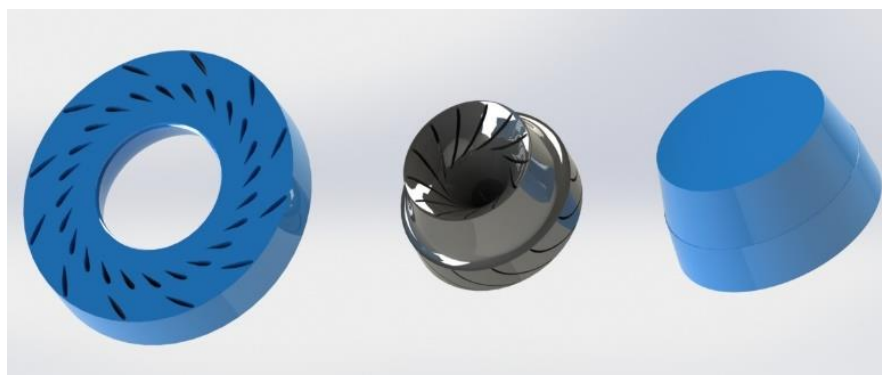

Fig. 2. Computational domain: stator, rotor, and draft tube

\section{Meshing}

The model is adjusted to reduce the number of elements to reasonable number of elements so that accurate numerical results may be achieved on this relatively affordable mesh. Tetrahedron elements are used to generate the mesh to account for the complex geometry. Figure 3 shows a general view of the domain mesh.

Table I shows a summary of the numerical mesh at full load condition (wicket gates opening position is at $85 \%$ ) with total number of elements 1022923 elements. For the part load position (wicket gates opening position is at 20\%), Table II shows summary of meshes at part load condition with total elements of 1233153 .
TABLE I. SUMMARY OF THE NUMERICAL MESH AT FULL LOAD

\begin{tabular}{lllll}
\hline Geometry & $\begin{array}{l}\text { Vane } \\
\text { shape }\end{array}$ & Blades & $\begin{array}{l}\text { Element } \\
\text { type }\end{array}$ & Elements \\
\hline Stator & 3D & 36 & Tetrahedron & 626252 \\
\hline Runner & 3D & 13 & Tetrahedron & 383882 \\
\hline Draft tube & 3D & - & Tetrahedron & 13789 \\
\hline
\end{tabular}

TABLE II. SUMMARY OF THE NUMERICAL MESH AT PART LOAD

\begin{tabular}{lllll}
\hline Geometry & $\begin{array}{l}\text { Vane } \\
\text { shape }\end{array}$ & Blades & Element type & $\begin{array}{l}\text { Ele } \\
\text { men } \\
\text { ts }\end{array}$ \\
\hline Stator & 3D & 36 & Tetrahedron & 731 \\
& & & & 367 \\
\hline Runner & 3D & 13 & Tetrahedron & 488 \\
& & & & 115 \\
\hline Draft tube & 3D & - & Tetrahedron & 146 \\
& & & & 71 \\
\hline
\end{tabular}

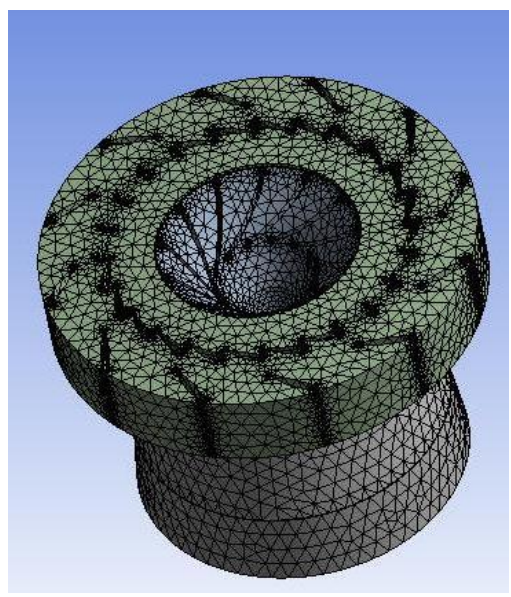

Fig. 3. Example of a figure caption. (figure caption)

\section{CFD solver setting}

In this case unsteady flow is chosen to account for the runner rotation. The turbulence model $\mathrm{k}$-epsilon realizable with scalable wall function is adopted to the turbulence model. Boundary condition are shown in details in Table III for both cases; full- and part-load. And the runner speed is 100 r.p.m for both cases.

TABLE III. TABLE STYLES

\begin{tabular}{|c|c|c|c|}
\cline { 3 - 4 } \multicolumn{2}{c|}{} & $\begin{array}{c}\text { Boundary } \\
\text { condition type }\end{array}$ & value \\
\hline \multirow{2}{*}{ Full load } & Inlet & Velocity-inlet & $5.21 \mathrm{~m} / \mathrm{s}$ \\
\cline { 2 - 4 } & Outlet & Pressure outlet & $0 \mathrm{bar}$ \\
\hline \multirow{2}{*}{ Part load } & Inlet & Velocity-inlet & $1.2 \mathrm{~m} / \mathrm{s}$ \\
\cline { 2 - 4 } & Outlet & Pressure outlet & 0 \\
\hline
\end{tabular}




\section{RESULTS AND DISCUSSION}

\section{A. Pressure field}

The pressure field throughout the Francis turbine is experiencing huge changes starting from the inlet, where high pressure exists due to the head of water pressure, and ending at the draft tube, where water is exposed to the atmospheric pressure. From inlet to outlet, the pressure changes in the Francis turbine components, i.e. stator, runner and draft tube.

Although the pressure at the turbine inlet is fixed (assuming no head variations), the pressure field changes within the turbine according to the turbine load. Actually, the pressure depends mainly on the load setting of the turbine because the fixed and moving vans are throttling and directing the flow so that the required load is achieved. This results in different pressure picture with each load setting (Figs. 4 and $5)$.

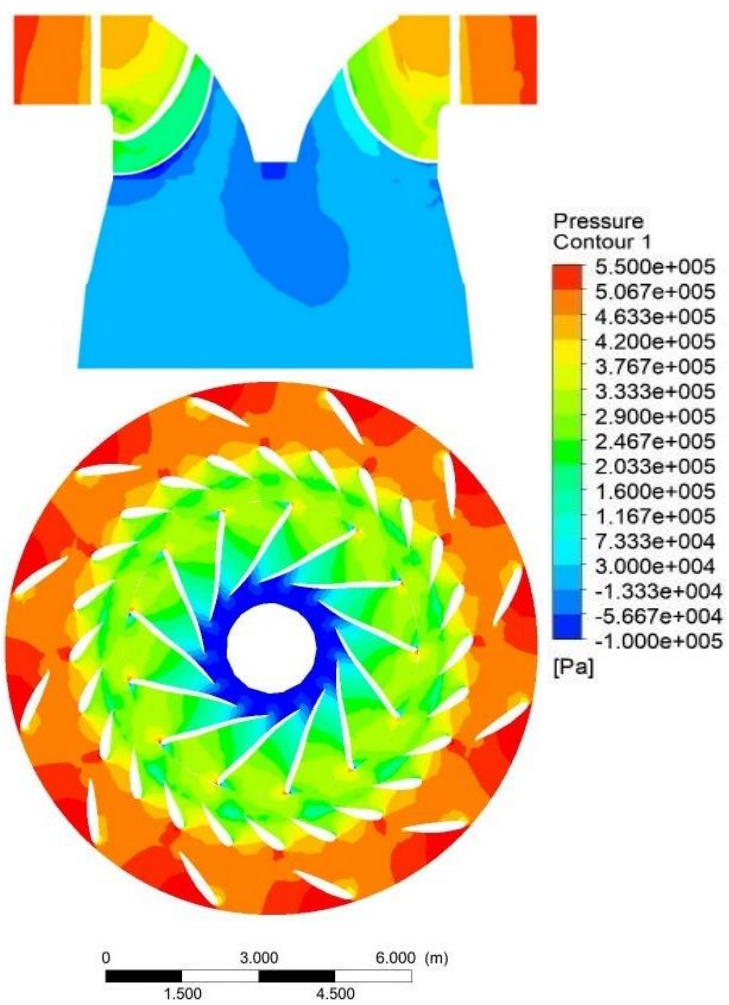

Fig. 4. Pressure filed at vertical and horizontal sections showing the pressure contours between the fixed and moving guide vanes and the runner for full load.

\section{B. Velocity field}

The flow field of the flow within the Francis turbine is very complex due to the geometry of the turbine components as well as the rotation of the runner. Moreover, the pressure and velocity are coupled according to the flow equations. Since the pressure field is shown in Sec. III.A to be very complex, consequently the flow field experiences huge changes throughout the Francis turbine.

Although the average velocity of the flow at the turbine inlet is fixed, the velocity field changes within the turbine according to the turbine load. The moving guide vanes changes the flow direction as well as the opening angle (and hence the velocity direction) to match the load requirements. This contributes as well to the total pressure within the turbine.
In order to monitor the flow field changes and their contributions in the RSI, the velocity field of the two cases, i.e. full- and part-load, is outlined in the next two sections in terms of velocity magnitude.

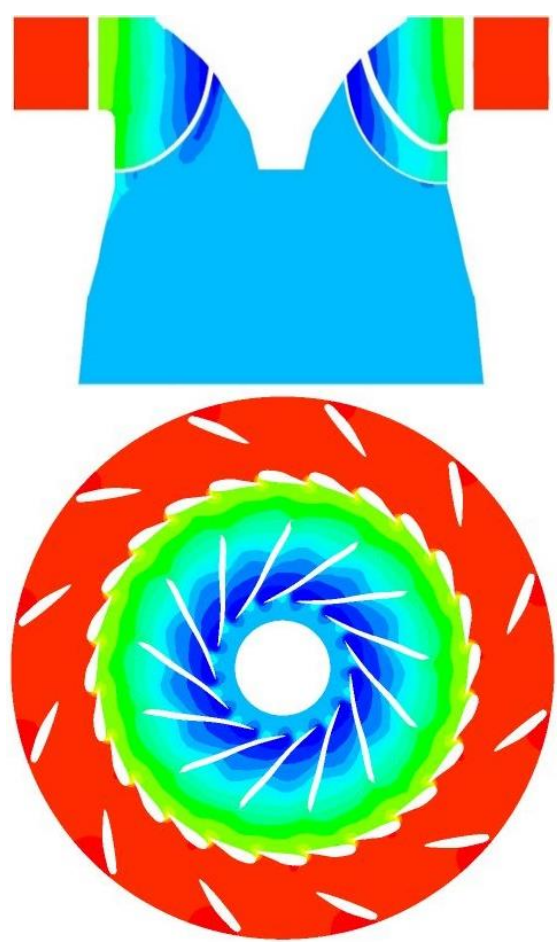

Fig. 5. Pressure filed at vertical and horizontal sections showing the pressure contours between the fixed and moving guide vanes and the runner for partial load

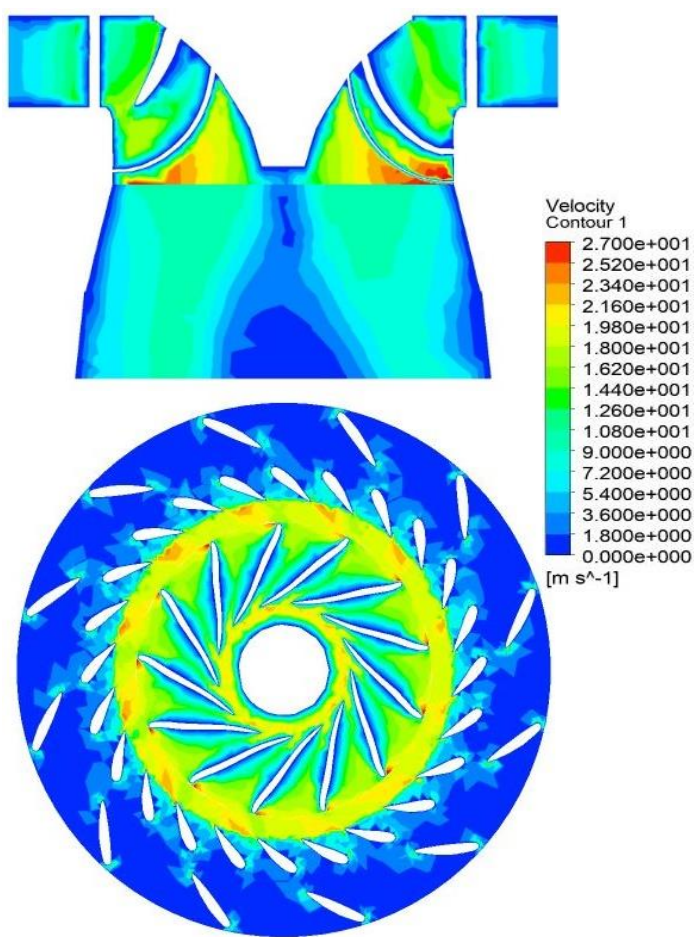

Fig. 6. Velocity filed at vertical and horizontal sections showing the velocity contours between the fixed and moving guide vanes and the runner for full load. 


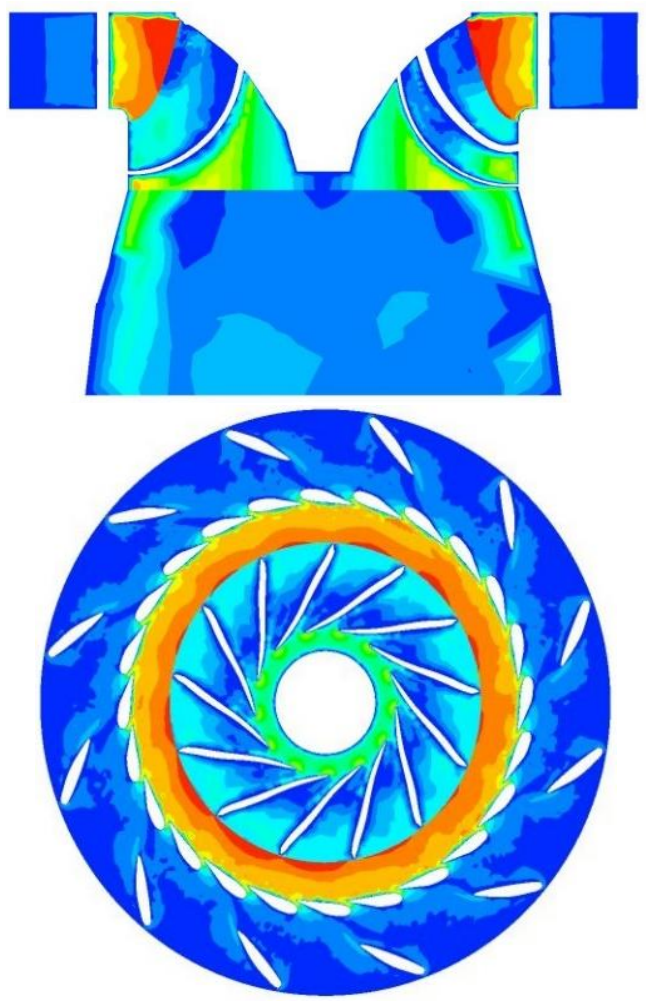

Fig. 7. Velocity filed at vertical and horizontal sections showing the velocity contours between the fixed and moving guide vanes and the runner for partial load.

\section{Turbulent intensity}

The turbulence intensity is defined as the ratio of the rootmean-square of the velocity fluctuations to the mean flow velocity[8]. The values of turbulent intensity is plotted in Fig. 8. The stator-rotor interaction increased the turbulent intensity. Also, the values are high near the vanes dues to the boundary layer and its associated turbulence.

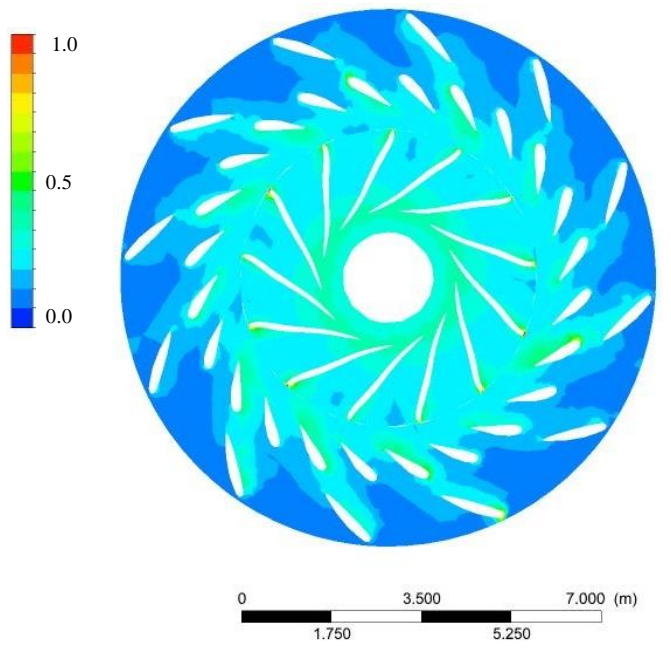

Fig. 8. Turbulent intensity full-load.

\section{Comparison with field measurements}

The pressure signal of pressure values taken during the simulation at monitoring point located within the simulation domain (after the moving guide vanes) at $x, y, z(5.1,12.9,2.7)$ is further processed to calculate the average pressure as well as the frequency of the pressure signal.
The measured average pressure at full load is $411.5 \mathrm{kPa}$ while at the partial load it is measured to be $252.8 \mathrm{kPa}$. The average values of the simulated static pressure using the current CFD study at the same location are $410.4 \mathrm{kPa}$ and $262.7 \mathrm{kPa}$ at full- and partial-load, respectively. The similar average values indicate that the quality of the CFD study is quite reseaonable (Fig. 9).

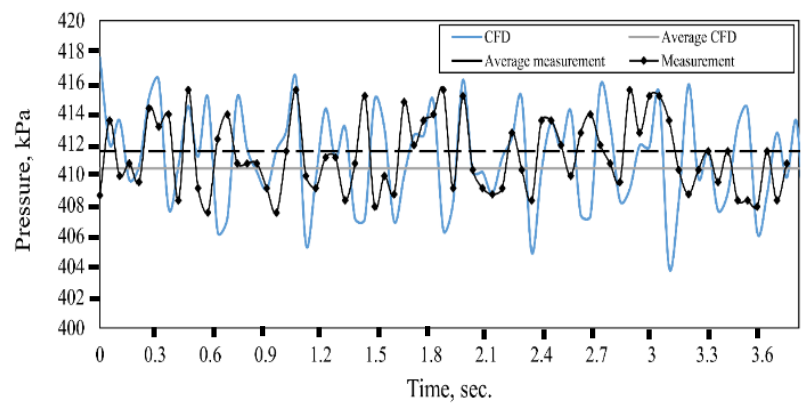

Fig. 9. Comparison between CFD and measurement pressure at a monitor point for the full load load

The pressure signal is processed using the Fast Fourier Transform (FFT). The calculated frequency of the signal is $21.67 \mathrm{~Hz}$ in both the full- and the partial-load. According to Equation1.2, the frequency of the RSI for the runner side is 21.67 Hz (Fig. 10).

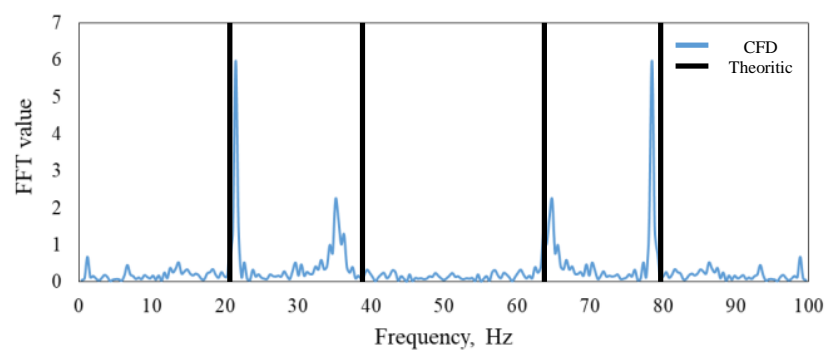

Fig. 10. .: Comparison between theoretical and CFD pressure frequency

\section{E. Frequency of pressure variation}

The FFT outputs are plotted for the pressure signals recorded from the simulation data at the stator and the runner in figure 11 and 12. Each figure shows the frequency spectra for both full- and part-load. The following points can be extracted from the FFT analysis:

- The FFT value in all full-load cases are higher than those in the part load indicating that the amplitude of the pressure fluctuations in case of full-load is much higher than those of the part load. A possible explanation for this might be that the flow velocity is much higher in case of full-load compared to the partload. This results in less RSI effect.

- The pressure signal at the stator, especially at the partload, is less affected by the runner rotation and hence showed less amplitude. The main interaction here is the cascade of the stator vanes (fixed and moving).

- The single most striking observation to emerge from this data is the value of the dominating frequency. It has an approximate value of $21 \mathrm{~Hz}$. The main source of the pressure fluctuations comes from the runner rotation. Recalling Equation1.2, the expected RSI 
frequency is calculated as $21.67 \mathrm{~Hz}$ (substituting for $n$ $=100 \mathrm{rpm}$ and $Z_{b}=13$ ). This finding is curtail in proving the quality of the CFD results.

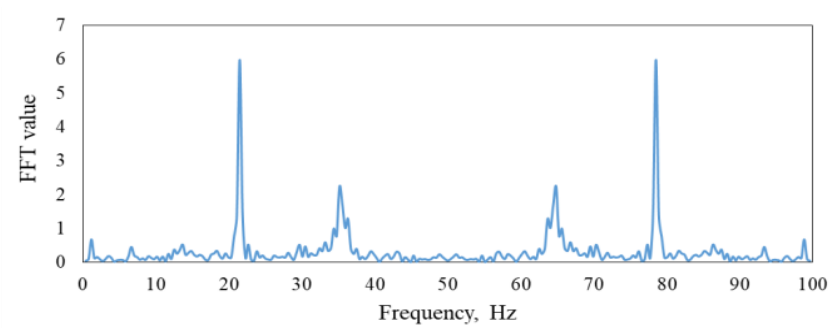

(a)

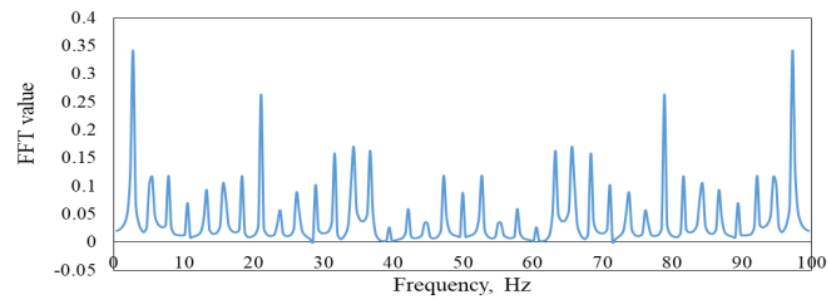

(b)

Fig. 11. Fourier transformed pressure signal in the stator (location S1) at (a) full-load and (b) part-load

- The other frequencies appeared in the frequency spectra are the secondary frequencies of the primary frequencies, while the other small frequencies are the frequencies resulting from the interactions with the small eddies $\left(f=f_{\text {primary }}-f_{\text {eddy }}\right)$.

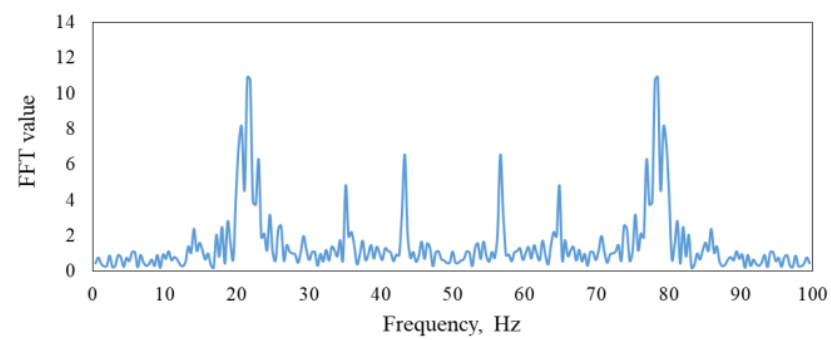

(a)

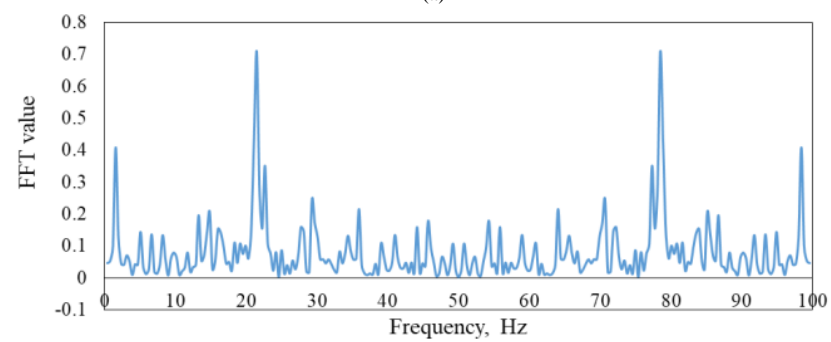

(b)

Fig. 12. Fourier transformed pressure signal in the runner (location R1) at (a) full-load and (b) part-load

\section{CONCLUSIONS}

The main goal of the current study was to investigate the flow in rotor-stator and the interaction in a full-scale Francis turbine under different operating conditions using state-ofthe-art CFD techniques and using the actual measurements of the power plant as boundary conditions. An in-situ measurement of the geometry dimensions is utilized to form the model. The following conclusions are extracted:

- This study provided two main deliverables: (1) a database for the CFD results of the flow simulations in two load capacities containing the important flow variables in all the numerical mesh and (2) the actual geometry of the Francis turbine which used in this study. These two deliverables are published in a public repository under license.

- The comparison between the measurement and the CFD results as well as the predicted and the theoretically calculated pressure variation frequency showed that CFD techniques can predict reasonably the pressure distributions and its frequencies within the Francis turbine.

- The numerical solution explained the RSI in Francis turbines by conducting unsteady flow simulation and to show the several flow features at different sections of the turbines. The results are analysed and their mutual effects are also correlated, to find out the outstanding flow parameters like velocity contours, pressure distribution and interaction between the stationary and rotating components.

- CFD technique proves to be a powerful analytical tool in simulating and evaluating the RSI in Francis turbines. The output of the CFD analysis of the flow field can be utilized qualitatively and graphically to verify safe operation and reasonable performance of the Francis turbine. Also, the unsteady flow and the pressure field are predicted by a time dependent analysis of the whole turbine.

- This study has found that generally the transient flow variables such as pressure and velocity can be utilized as bases for evaluating the RSI characteristics in the turbine in full- and part-load. The internal flow features in a Francis turbine are described and resulting phenomena are addressed.

\section{ACKNOWLEDGMENT}

The support from all the staff of the High Dam Power Station is highly appreciated. Without this support, it would be impossible to carry out this study.

\section{REFERENCES}

[1] E. T. Layton, From rule of thumb to scientific engineering: James B. Francis and the invention of the Francis Turbine. Stony Brook N.Y.: State University of New York. Research Foundation, 1992.

[2] D. R. Giosio et al., "Rapid Reserve Generation from a Francis Turbine for System Frequency Control," Energies, vol. 10, no. 4, p. 496, Apr. 2017.

[3] R. P. Dring, H. D. Joslyn, L. W. Hardin, and J. H. Wagner, "Turbine Rotor-Stator Interaction,” J. Eng. Power, vol. 104, no. 4, p. 729, Oct. 1982

[4] I. ANSYS, ANSYS® Academic Research Mechanical, Release 18.1, Help System, Coupled Field Analysis Guide. 2017

[5] G. D. Ciocan, F. Avellan, and J.-L. Kueny, "Optical Measurement Techniques for Experimental Analysis of Hydraulic Turbines Rotor - 
Stator Interaction," Proc. ASME Fluids Eng. Div. Summer Meet. Boston, Massachusetts, USA, June 11-15, 2000.

[6] N. Arndt, A. J. Acosta, C. E. Brennen, and T. K. Caughey, "RotorStator Interaction in a Diffuser Pump," J. Turbomach., vol. 111, no. 3 , p. 213, Jul. 1989.

[7] S. Kaji and T. Okazaki, "Generation of sound by rotor-stator interaction,” J. Sound Vib., vol. 13, no. 3, pp. 281-307, Nov. 1970.

[8] T. Kawakubo, "Unsteady Rotor-Stator Interaction of a Radial-Inflow Turbine With Variable Nozzle Vanes," in Volume 7: Turbomachinery, Parts A, B, and C, 2010, pp. 2075-2084G. Eason, B. Noble, and I. N. Sneddon, "On certain integrals of Lipschitz-Hankel type involving products of Bessel functions," Phil. Trans. Roy. Soc. London, vol. A247, pp. 529-551, April 1955. (references)

[9] T. Meakhail and S. O. Park, "A Study of Impeller-Diffuser-Volute Interaction in a Centrifugal Fan," J. Turbomach., vol. 127, no. 1, p. 84, Jan. 2005

[10] C. Trivedi, M. J. Cervantes, B. K. Gandhi, and O. G. Dahlhaug, "Experimental and Numerical Studies for a High Head Francis Turbine at Several Operating Points," J. Fluids Eng., vol. 135, no. 11, p. 111102, Aug. 2013 